\title{
The Stockholm Spinal Cord Injury Study. 3. Health-related issues of the Swedish annual level-of-living survey in SCI subjects and controls
}

\author{
$\mathrm{R}_{\text {Levi }}{ }^{1,2}, \mathrm{C}$ Hultling ${ }^{1}$ and $\AA$ Seiger ${ }^{1,2}$ \\ ${ }^{1}$ Solberga SCI Research Project, Karolinska Institute, S-126 91 Stockholm; ${ }^{2}$ Department of Clinical Neuroscience \\ and Family Medicine, Karolinska Institute, Huddinge University Hospital, Stockholm, Sweden
}

\begin{abstract}
In previous articles on the Stockholm Spinal Cord Injury Study (SSCIS), we have reported the frequent occurrence of medical problems in a near-total regional SCI population comprising 353 subjects. This present study further investigates health-related issues in this SCI population, by a level-of-living survey that has been used annually on $8000-14000$ Swedes since 1974. The health-focused version of this survey was used for data collection in those 326 subjects in the SSCIS who were residents of the Greater Stockholm area. Subjects of the SSCIS living on the island of Gotland were excluded because they represented a sociodemographically different (rural) population. The normative material consisted of 1978 interviews of residents of the Greater Stockholm area, provided by the Swedish Bureau of Statistics. Results show a higher utilisation of health care resources among SCI subjects, shown by higher rates of long-term sick leave and sick pension, and more treatment as inpatients, emergency room attendees, and outpatients. Pain, bladder problems, and psychological symptoms are more commonly reported by SCI subjects. Medications such as antibiotics, analgesics, sedatives, hypnotics and laxatives are used more frequently in the SCI group. In contrast, no statistically significant differences were found as regards reported prevalence of diseases other than SCI, including diabetes, hypertension and cardiac disease. The results thus verify the impression from our previous studies of a clearly increased morbidity among these SCI subjects. The increased morbidity seems to be accounted for by the SCI itself, or conditions directly caused by it.
\end{abstract}

Keywords: spinal cord injuries; Stockholm Spinal Cord Injury Study; health related issues; epidemiology; outcome; complications

\section{Introduction}

Due to the considerably improved life expectancy of people with traumatic spinal cord injuries (SCI) during the last decades, issues regarding their long term management have become increasingly relevant. This is reflected in a growing literature dealing with aging, morbidity, mortality and quality of life among chronic SCI subjects. ${ }^{1}$ Major obstacles in the evaluation assessment of such issues have been high drop-out rates and/or biased selection due to limited access to the total SCI population. Many SCI research centres share catchment areas with other hospitals working with SCI, and/or serve as tertiary referral centres for particular SCI subgroups. This, inevitably, leads to difficulties when attempting to assess the natural history of SCI. The Swedish health care system, with its tradition of socialised medicine and comprehensive documentation of patient care, facilitates the undertaking of such epidemiological studies.

The Stockholm Spinal Cord Injury Study (SSCIS) describes the health status among a near-total regional population of chronic SCI subjects of traumatic aeti- ology. Previous articles stemming from the SSCIS have focused on medical problems in the total sample, as well as in subgroups defined by commonly used clinical patient variables. ${ }^{1,2}$ Chronic SCI subjects generally reported a multitude of medical problems, with some differences in vulnerability associated with gender, age at injury and extent of neurological compromise.

The data presented in previous articles were obtained by interviews according to semi-structured protocols, physical examination and review of medical records. This method provided a detailed picture of the study group, but was less well suited for collection of normative data.

Normative data are crucial for evaluating whether SCI subjects are more prone to experience health problems than others. This is especially relevant as regards the conditions not directly associated with the SCI as such, and particularly those with a high expected prevalence in the general population. It was therefore decided to include in the SSCIS a survey for the assessment of health-related issues which has been used in other population groups. Such a survey, although less detailed, could provide the possibility of a comparison 
between our group and normative data. The results from this survey are presented herein.

Thus, the aim of this subset of the SSCIS was to evaluate if and how the health profile in chronic SCI subjects differs from that of the general population.

\section{Subjects and methods}

The SSCIS population comprised 353 SCI subjects in the Greater Stockholm area. and the island of Gotland, representing the catchment area of the regional SCI services. The study group included $93 \%$ of the total regional SCI population. A detailed description of the steps for identification of the study group, as well as its characteristics has been published previously. ${ }^{1,2}$ In the present study, only the 326 subjects (262 males, 64 females) living in the Greater Stockholm area were included, since Gotland represents a distinctly rural rather than urban area. The number of subjects from this district were too few to allow a separate statistical analysis.

The so-called Swedish Annual Level-of-Living Survey (Undersökning av Levnadsförhållanden, ULF) was chosen as the investigative instrument for a number of reasons. Firstly it was developed by the Swedish Bureau of Statistics under instruction from the Swedish Parliament, to carry out annual national level-of-living surveys. Second, these surveys are based on nationwide samples of the whole population in the ages 16-84 years, and have been in use for 21 years. Each annual sample comprises 8000-14000 individuals. Third, this survey programme was designed as a data collection tool for analysis of components considered most essential to the welfare situation, viz health, employment, education, economy, housing, social relations, leisure, political resources, safety and security, and transport. Fourth, these surveys are coordinated in detail as regards indicators, definitions, training of interviewers and coding personnel, continuous quality controls, analysis and reporting models. The findings of the surveys are published in the series Living Conditions, which forms part of the Official Statistics of Sweden. Information as regards development of the surveys, quality issues, and technical issues is given elsewhere. ${ }^{3-7}$

Some variations in emphasis among the components of the ULF do exist. The central variables of each component are measured each year. Additionally, a more detailed survey of each component is added to this basic information periodically (in the component rotation). In 1988-89, surveys centred on health issues were used for this reason. Therefore, this particular variant of the ULF was used in the present study.

The survey of the study group was conducted by the SCI Clinic social worker according to the training programme on the ULF, provided by the Swedish Bureau of Statistics. The interviewer followed a structured protocol. Straight-forward questions were given in a totally standardised manner. The interviewer was not allowed to elaborate on the questions or answers, but was instructed to adhere strictly to the protocol.
The average time for completion of the interview is set to $60 \mathrm{~min}$ in a single session.

The control material consisted of 1978 interviews (960 males, 1018 females: age range 16-74, mean 42) made by the Swedish Bureau of Statistics in 1988-89 according to the health centre ULF used in these years. The material represented persons living in the same region as the study population, ie the Greater Stockholm area. ${ }^{8}$ Transfer of data to computer was done by staff at the Swedish Bureau of Statistics.

\section{Statistical methods}

Due to differences in age and sex distributions between the study group and the normative material, with younger males dominating the SCI group, a statistical method for controlling these variables was imposed. The socioeconomic status of the subject is affected by the SCI and therefore a potential indicator of the consequences of the SCI rather than a confounding factor. Therefore, matching was made based on parental socioeconomic situation. Briefly, this is assessed by categorisation of parental occupation according to the protocols of the ULF. Hereby, the occupation of the parent with the highest education is used as indicator of socioeconomic status. Information regarding this was provided by the ULF survey. Such factors may have a profound influence on the variables under study.

For the comparison of proportions, ie the presence of a given factor amongst SSCIS individuals in comparison to the normative sample, the odds ratio was used as an estimation of association. ${ }^{9}$ In addition, as there are some demographic differences between these samples regarding age and sex distributions as well as socioeconomic background, it was decided to estimate an 'adjusted odds ratio', while statistically controlling for these 'covariates'. This estimation was computed in a multivariate logistic regression analysis. ${ }^{10}$

In this regression method, weights are assigned to independent variables, in such a way that the prediction of a given event (ie the binary dependent variable, constituting the occurrence of a symptom or disease) is maximised. These regression weights can be converted into and then interpreted as odds ratios, quantifying the partial association of a risk variable with the occurrence of a given symptom. In this present study, age, sex, socioeconomic background, and SSCIS versus normative group membership are concurrently used to predict occurrence of specific attributes or symptoms. In these multivariate analyses we are particularly interested in the regression weight assigned to the SSCIS/normative group membership variable. We have labelled this coefficient the 'adjusted odds ratio' because it is an odds ratio statistically adjusted for the concurrently predictive effects of age, sex and socioeconomic background on symptom occurrence.

The exact $P$ values have been given in order to allow judgement in terms of type I errors. 


\section{Results}

For purposes of presentation of data in this article, the terms used in the survey have been translated from Swedish to English. In the Swedish language, colloquialisms rather than Latin terms are frequently used when describing medical matters. This accounts for some instances of lack of teminological stringency in the tables.

\section{Utilisation of health care resources}

Table 1 depicts the percentages in utilisation of health care resources in SCI subjects, and odds ratios when comparing with the normative material. SCI subjects report that their health situation is worse than controls; that they have a much higher rate of long term sick leave and sick pension; that they have more contacts with emergency rooms, district nurses, physiotherapists; and that they are treated as inpatients much more often than controls.

\section{Prevalence of medical symptoms}

Table 2 shows percentages of medical symptoms in the SCI group, and odds ratios when comparing with the normative group. It can be seen that SCI subjects report more pain in all locations; more bladder problems; and more fatigue, anxiety, and insomnia.

\section{Prevalence of diagnosed conditions}

In Table 3, prevalences of diagnosed diseases are seen for the SCI group, as well as odds ratios in comparison to the normative group. In summary, the table shows

Table 1 Indicators of general health

\begin{tabular}{|c|c|c|c|c|c|}
\hline \multirow[t]{2}{*}{ Item } & \multirow{2}{*}{$\begin{array}{c}S C I \\
\%\end{array}$} & \multicolumn{2}{|c|}{ SCI/Controls } & \multicolumn{2}{|c|}{ SCI/Controls } \\
\hline & & Odds-ratio & $P$ & $\begin{array}{l}\text { Adjusted } \\
\text { odds-ratio }\end{array}$ & $P$ \\
\hline Bad general state of health & 42 & 3.03 & 0.0001 & 3.33 & 0.0001 \\
\hline $\begin{array}{l}\text { Inferior state of health compared } \\
\text { with contemporaries }\end{array}$ & 47 & 1.85 & 0.0001 & 1.80 & 0.0001 \\
\hline Daily smoking & 38 & 1.36 & 0.0143 & 1.29 & 0.0541 \\
\hline No physical exercise & 34 & 3.9 & 0.0001 & 3.9 & 0.0001 \\
\hline Regular physical exercise & 20 & 1.9 & 0.0001 & 1.8 & 0.0006 \\
\hline Illness during the last 2 weeks & 23 & 1.88 & 0.0001 & 1.95 & 0.0001 \\
\hline Sick leave in the last 2 weeks & 11 & 1.01 & 0.9641 & 0.99 & 0.9871 \\
\hline $\begin{array}{l}\text { Attended an emergency room } \\
\text { within the last } 3 \text { months }\end{array}$ & 14 & 1.49 & 0.0256 & 1.59 & 0.0137 \\
\hline $\begin{array}{l}\text { Not contacted physician within } \\
\text { the last } 3 \text { months in spite of need }\end{array}$ & 21 & 2.04 & 0.0001 & 2.05 & 0.0001 \\
\hline $\begin{array}{l}\text { Admitted to hospital within the } \\
\text { last } 3 \text { months }\end{array}$ & 19 & 5.83 & 0.0001 & 6.97 & 0.0001 \\
\hline $\begin{array}{l}\text { Visited the district nurse within } \\
\text { the last } 3 \text { months }\end{array}$ & 35 & 7.01 & 0.0001 & 7.65 & 0.0001 \\
\hline Receives physiotherapy & 32 & 7.92 & 0.0001 & 9.40 & 0.0001 \\
\hline Gainfully employed & 50 & 0.35 & 0.0001 & 0.14 & 0.0001 \\
\hline Early retirement & 29 & 15.77 & 0.0001 & 15.94 & 0.0001 \\
\hline
\end{tabular}

Table 2 Prevalences of medical symptoms

\begin{tabular}{|c|c|c|c|c|c|}
\hline \multirow[t]{2}{*}{ Symptom } & \multirow{2}{*}{$\begin{array}{c}S C I \\
\%\end{array}$} & \multicolumn{2}{|c|}{ SCI/Controls } & \multicolumn{2}{|c|}{ SCI/Controls } \\
\hline & & Odds-ratio & $P$ & $\begin{array}{l}\text { Adjusted } \\
\text { odds-ratio }\end{array}$ & $P$ \\
\hline Shoulder/neck pain & 56 & 2.82 & 0.0001 & 3.68 & 0.0001 \\
\hline Eczema/skin rash & 24 & 1.65 & 0.0005 & 1.86 & 0.0005 \\
\hline Hip/back pain & 49 & 1.96 & 0.0001 & 2.12 & 0.0001 \\
\hline Cystitis/urinary urgency & 25 & 5.49 & 0.0001 & 7.10 & 0.0001 \\
\hline Extremity pain & 47 & 3.05 & 0.0001 & 3.72 & 0.0001 \\
\hline Anxiety & 28 & 2.87 & 0.0001 & 3.73 & 0.0001 \\
\hline Sleep disturbance & 35 & 3.20 & 0.0001 & 3.53 & 0.0001 \\
\hline Fatigue & 46 & 1.74 & 0.0001 & 2.11 & 0.0001 \\
\hline Headache & 15 & 1.20 & 0.2724 & 1.44 & 0.0383 \\
\hline
\end{tabular}


that SCI subjects report the same frequencies of diagnosed conditions, or often less, than controls, except for obesity.

\section{Prevalence of medication}

Table 4 depicts percentages in utilisation of medications in SCI subjects, and odds-ratios when comparing with the normative material. SCI subjects use more antibiotics, laxatives, analgesics, sedatives, hypnotics, skin medications and vitamins than controls; and no more cardiotropic and antihypertensive drugs, as well as some other medications as specified in the table.

\section{Discussion}

In previous reports from the SSCIS, a detailed account of the morbidity in the study group has been given. The present study provides the possibility of comparisons with normative data from the greater Stockholm area. After statistically controlling for differences in age, sex and socioeconomic background, it is evident that chronic SCI subjects experience significantly more health problems than the general population. This health profile is reflected in a higher prevalence of many medical symptoms, a higher use of medications, as well as more frequent contacts with medical and paramedical caregivers.

Table 3 Prevalence of medical disorders

\begin{tabular}{|c|c|c|c|c|c|}
\hline \multirow[t]{2}{*}{ Disorder } & \multirow{2}{*}{$\begin{array}{c}S C I \\
\%\end{array}$} & \multicolumn{2}{|c|}{ SCI/Controls } & \multicolumn{2}{|c|}{ SCI/Controls } \\
\hline & & Odds-ratio & $P$ & $\begin{array}{c}\text { Adjusted } \\
\text { odds-ratio }\end{array}$ & $P$ \\
\hline Tumour (all locations) & 0.3 & 0.61 & 0.6334 & 0.76 & 0.7941 \\
\hline Endocrine & 2 & 0.48 & 0.0897 & 0.68 & 0.3894 \\
\hline Diabetes mellitus & 1 & 1.01 & 0.9809 & 1.20 & 0.7447 \\
\hline Mental & 2 & 0.65 & 0.3714 & 0.67 & 0.4226 \\
\hline Neurological (excl. SCI) & 2 & 0.43 & 0.031 & 0.40 & 0.0240 \\
\hline Seizure & 1 & 1.51 & 0.6042 & 1.12 & 0.8322 \\
\hline Eye & 1 & 0.53 & 0.3849 & 0.54 & 0.4218 \\
\hline Ear, nose and throat & $0^{\mathrm{a}}$ & & & & \\
\hline Circulatory & 2 & 0.22 & 0.0003 & 0.25 & 0.014 \\
\hline Hypertension & $0^{\mathrm{b}}$ & & & & \\
\hline Cardiac & 2 & 0.64 & 0.3466 & 0.7216 & 0.5080 \\
\hline Respiratory & 9 & 0.24 & 0.0167 & 0.29 & 0.0389 \\
\hline Digestive & 3 & 0.96 & 0.9035 & 0.96 & 0.9104 \\
\hline Urogenital & 1 & 0.32 & 0.1222 & 0.48 & 0.3204 \\
\hline Skin (excl. decubiti) & 1 & 0.37 & 0.0997 & 0.36 & 0.0890 \\
\hline Psoriasis & 4 & 1.33 & 0.3449 & 1.10 & 0.7574 \\
\hline Musculoskeletal & 5 & 0.37 & 0.0001 & 0.42 & 0.0012 \\
\hline Congenital & 0.3 & 1.21 & 0.8596 & 0.51 & 0.5651 \\
\hline Obesity & 27 & 2.31 & 0.0001 & 2.50 & 0.0001 \\
\hline Asthma & 3 & 1.01 & 0.9613 & 1.05 & 0.8866 \\
\hline
\end{tabular}

aControls $2 \%$

bControls 5\%

Table 4 Prevalence of medication

\begin{tabular}{|c|c|c|c|c|c|}
\hline \multirow[t]{2}{*}{ Medication } & \multirow{2}{*}{$\begin{array}{c}S C I \\
\%\end{array}$} & \multicolumn{2}{|c|}{ SCI/Controls } & \multicolumn{2}{|c|}{ SCI/Controls } \\
\hline & & Odds-ratio & $P$ & $\begin{array}{c}\text { Adjusted } \\
\text { odds-ratio }\end{array}$ & $P$ \\
\hline Cough & 11 & 1.33 & 0.1342 & 1.63 & 0.0152 \\
\hline Antibiotics & 15 & 5.74 & 0.0001 & 6.33 & 0.0001 \\
\hline Ointments & 26 & 2.63 & 0.0001 & 2.78 & 0.0001 \\
\hline Laxatives & 35 & 34.95 & 0.0001 & 42.32 & 0.0001 \\
\hline Iron & 2 & 0.37 & 0.0333 & 0.46 & 0.0981 \\
\hline Vitamins & 34 & 1.55 & 0.0006 & 1.89 & 0.0001 \\
\hline Cardiac & 2 & 0.46 & 0.0735 & 0.69 & 0.4041 \\
\hline Antihypertensive & 4 & 0.69 & 0.2165 & 0.83 & 0.5577 \\
\hline Herbal & 9 & 1.06 & 0.7887 & 1.49 & 0.0758 \\
\hline Analgesics (over the counter) & 19 & 0.58 & 0.0003 & 0.70 & 0.0237 \\
\hline Analgesics (prescription) & 27 & 4.50 & 0.0001 & 5.22 & 0.0001 \\
\hline Sleep & 9 & 2.86 & 0.0001 & 3.24 & 0.0001 \\
\hline Tranquillisers & 9 & 3.39 & 0.0001 & 3.56 & 0.0001 \\
\hline
\end{tabular}


In addition to this quantitative aspect, some comments regarding the qualitative aspect of health problems in SCI subjects can be made.

The higher prevalence of ill health seems to reflect dysfunctions related to the SCI, eg pain, bladder dysfunction, and skin problems. By contrast, prevalence of non-SCI-related diseases does not differ significantly from the general population. This health profile is further corroborated by the types of medications used by the SCI group, eg antibiotics, analgesics and laxatives.

The lack of differences in prevalence of diabetes, high blood pressure, and cardiac disease among SCI subjects and controls, is noteworthy since some studies have suggested an increased risk for such conditions among SCI survivors. ${ }^{11-14}$ Our findings reflect diagnosed conditions, and not subclinical and/or as yet undiagnosed cases. It remains to be ascertained whether such a hypothetical 'false negative' group would be large enough to change the picture significantly.

It is difficult to interpret the frequent occurrence of mental symptoms in the SCI group. Clearly, there is experience of greater fatigue and anxiety than in the controls. However, it is not possible to determine at this stage whether this reflects differences in premorbid personality traits, or could be explained by reactions to the physical and psychological impact of chronic SCI. Nevertheless, it serves to emphasise the need for inclusion of psychosocial counselling as part of the long term management of SCI.

It should be noted that while the controls were interviewed in 1988 and 1989, SCI cases were interviewed in 1991 to 1994 . This could account for at least part of the observed difference between cases and controls. However, no major changes in prescription practices, availability and affordability of medications, or access to or utilisation of health care services has been observed during this limited time span, as can be seen from the annual surveys of the general population undertaken by the Swedish Bureau of Statistics. ${ }^{8}$

Our results may be put in the context of some previous work on this topic. Berkowitz et al, in a book on economic consequences of $\mathrm{SCI},{ }^{15}$ reported a higher propensity for hospitalisation and medical practitioner visits in SCI subjects than in their non-disabled counterparts. Furthermore, the utilisation of prescription and non-prescription drugs was assessed, with findings largely consistent with ours. DeVivo et al found hospital usage to be considerably higher in a SCI group than in the general population. Whiteneck et al,${ }^{17}$ when assessing current health status in their study of a large cohort of SCI patients in Great Britain, also found frequent reports of, among other things, pain, bladder and skin problems. Frost et $a l^{18}$ showed a high rate of emergency room utilisation among persons with SCI.

In conclusion, the present study provides data on health-related issues from a near total regional SCI sample and a normative material from the same region. After statistical control for differences in age, sex and the socioeconomic background, it is evident that the SCI group experiences significantly more health prob- lems, as reflected in more frequent contacts with the health care system, more frequent use of several medications, and a higher prevalence of medical symptoms. By contrast, the prevalences of conditions not directly related to the SCI are not overrepresented in the SCI group. Thus, we find no support for the postulated increase in risk for cardiac disease, hypertension or diabetes among these SCI subjects.

\section{Acknowledgements}

This study was supported by The Spinalis Foundation, the Swedish Medical Research Council (grant 06555), Allmänna Arvsfonden and The Swedish National Board of Health and Welfare. The authors thank Ms Susanne Wikblad for excellent secretarial help, Ms Åsa Llinares for performing the interviews, and Mr Petter Gustavsson MSc for statistical assistance.

\section{References}

1 Levi R, Hultling C, Nash M, Seiger $\AA$. The Stockholm Spinal Cord Injury Study: 1. Medical problems in a regional SCI population. Paraplegia 1995; 33: 308-315.

2 Levi R, Hultling C, Seiger $\AA$. The Stockholm Spinal Cord Injury Study: 2. Associations between clinical patient descriptors and post-acute medical problems. Paraplegia 1995; 33: 585-594.

3 Thorslund M, Wärneryd B. Testing/assessing question quality. Some Swedish experiences. J Official Statistics, 1985; 1: 159-178.

4 Thorslund M, Wärneryd B. Methodological research in the Swedish surveys of living conditions. Problems of measurement and data collection. Soc Indicators Res 1985; 16: 77-95.

5 Wikman A, Wärneryd B. Measurement errors in survey questions: explaining response variability. Soc Indicators Res 1990; 22: $199-212$.

6 Lindström H. Non-Response Errors in Sample Surveys. SCB Publ., Orebro, Sweden, 1983

7 The Living Conditions of the Social Assistance Clients. Report No 52, Living Conditions. SCB Publ., Orebro, Sweden, 1987.

8 The Annual Level-of-Living Survey. SCB Publ., Orebro, Sweden, 1990.

9 Fleiss JL. Statistical Methods for Rates and Proportions, 2nd edn. John Wiley \& Sons: New York, 1981.

10 Hosmer DW, Lemeshow S. Applied Logistic Regression. John Wiley \& Sons: New York, 1989.

11 Duckworth WC et al. Glucose intolerance due to insulin resistance in patients with spinal cord injuries. Diabetes 1980; 29: 906-910.

12 Duckworth WC, Jallepalli P, Solomon SS. Glucose intolerance in spinal cord injury. Arch Phys Med Rehabil 1983; 64: 107-110.

13 Bauman WA et al. Depressed serum high density lipoprotein cholesterol levels in veterans with spinal cord injury. Paraplegia 1992; 30: 697-703.

14 Yekutiel $\mathrm{M}$ et al. The prevalence of hypertension ischemic heart disease and diabetes in traumatic SCI and in those with lower extremity amputations. Paraplegia 1989; 27: 58-62.

15 Berkowitz M, Harvey C, Greene CG, Wilson SE. The Economic Consequences of Traumatic Spinal Cord Injury. Demos Publication, 1992, pp 81-90, 96-100.

16 DeVivo MJ et al. A cross-sectional study of the relationship between age and current health status for persons with spinal cord injuries. Paraplegia 1992; 30: 820-827.

17 Whiteneck GG et al. Mortality, morbidity and psychosocial outcomes of persons spinal cord injured more than 20 years ago. Paraplegia 1992; 30: 617-630.

18 Frost F, Lee SB, Zimmerman K, Maynard F. Incidence and cost of emergency department visits in a large outpatient SCI population. J Am Paraplegia Soc 1994; 17: 229-230. 